\title{
Technology-Facilitated Abuse Prevalence and Associations Among a Nationally Representative Sample of Young Men
}

Laura Seewald, $M D^{1}$

Tova B. Walsh, PhD, MSW'

Richard M. Tolman, $P b D, M S W^{3}$

Shawna J. Lee, $P b D, M S W, M P P, M S^{3}$

Lauren A. Reed, PbD, MSW, MS

Quyen Ngo, PbD, $L P^{5}$

Vijay Singh, $M D, M P H, M S^{1,6,7}$

'Department of Emergency Medicine, Medical School, University of Michigan, Ann Arbor, Michigan

${ }^{2}$ School of Social Work, University of Wisconsin, Madison, Wisconsin

${ }^{3}$ School of Social Work, University of Michigan, Ann Arbor, Michigan

${ }^{4}$ School of Social Work, Arizona State University, Phoenix, Arizona

${ }^{5}$ Butler Center for Research, Hazelden Betty Ford Foundation, Center City, Minnesota

${ }^{6}$ Department of Family Medicine, Medical School, University of Michigan, Ann Arbor, Michigan

${ }^{7}$ Department of Internal Medicine, Medical School, University of Michigan, Ann Arbor, Michigan

Conflicts of interest: authors report none.

\section{CORRESPONDING AUTHOR}

Laura Seewald

Department of Emergency Medicine

University of Michigan

1500 E Medical Center Dr

Ann Arbor, MI 48109

lseewald@umich.edu

\begin{abstract}
PURPOSE We undertook a study to determine the prevalence and associations of technology-facilitated abuse (TFA)-insults, harassment, coercion, or threats carried out using digital tools such as smartphones and computers-among a US nationally representative sample of young men.
\end{abstract}

METHODS Analyses were based on 1,079 men aged 18 to 35 years who completed questionnaires during August and September of 2014 and reported ever having been in a romantic relationship. We used validated measures to assess demographics, health service use, mental health and substance use, and TFA delivered to and received from partners in the past year. We calculated survey-weighted descriptive statistics and conducted multinomial logistic regression analysis.

RESULTS Overall, $4.1 \%$ of men reported delivering TFA only, $8.0 \%$ receiving TFA only, and $25.6 \%$ both delivering and receiving TFA. Men were more likely to report only delivering TFA if they identified as Hispanic (adjusted odds ratio [AOR] $=2.72 ; 95 \% \mathrm{Cl}, 1.13$ to 6.57), used marijuana ( $A O R=1.31 ; 95 \% \mathrm{Cl}, 1.02$ to 1.68$)$, and used prescription opioids for nonmedical reasons (AOR 2.86; $95 \% \mathrm{Cl}, 1.48$ to 5.54). Men were more likely to report only receiving TFA if they identified as Hispanic (AOR $=2.55 ; 95 \% \mathrm{Cl}, 1.01$ to 6.43 ) and used prescription opioids for nonmedical reasons (AOR $=2.43 ; 95 \% \mathrm{Cl}, 1.34$ to 4.39), whereas a primary care connection appeared protective ( $\mathrm{AOR}=0.43 ; 95 \% \mathrm{Cl}, 0.22$ to 0.86 ). Men were more likely to report both delivering and receiving TFA if they identified as nonHispanic Black (AOR = 2.83; 95\% Cl, 1.44 to 5.58), owned a smartphone (AOR = 1.80; $95 \% \mathrm{Cl}, 1.05$ to 3.09$)$, had ever had mental health care visits ( $\mathrm{AOR}=1.86 ; 95 \% \mathrm{Cl}, 1.16$ to 2.98), misused alcohol ( $A O R=1.10 ; 95 \% \mathrm{Cl}, 1.04$ to 1.17$)$, and used prescription opioids for nonmedical reasons ( $A O R=1.79 ; 95 \% \mathrm{Cl}, 1.04$ to 3.08$)$.

CONCLUSIONS We found that TFA was prevalent among young men, with 1 in 25 reporting delivery only, 1 in 12 reporting receipt only, and 1 in 4 reporting both. Primary care physicians can consider assessing TFA among male patients and developing interventions to mitigate this behavior.

\section{VISUAL ABSTRACT \\ Ann Fam Med 2022;20:12-17. https://doi.org/10.1370/afm.2758.}

\section{INTRODUCTION}

$\mathrm{A}$ dults in the United States often use technology-facilitated communication tools to form and maintain intimate relationships. Among US adults, $81 \%$ own a smartphone, $75 \%$ own a desktop or laptop computer, and almost $50 \%$ own a tablet. ${ }^{1}$ For couples who report that digital tools have had at least a minor impact on their relationships, $74 \%$ report that these tools have had a positive impact. ${ }^{2}$ As digital tools become integrated into intimate relationships, however, intimate partner violence delivered by technological means has become a public health concern. ${ }^{3}$

Technology-facilitated abuse (TFA) refers to use of technology as the medium through which abusive behavior occurs. TFA can include using cell phones, text messages, e-mails, or social media sites to call a partner names, put them down, insult them, or send unwanted or nonstop texts or calls or online messages asking where partners were, what they were doing, or whom they were with. ${ }^{4}$ Other forms of TFA include using digital tools to threaten physical violence, to pressure or coerce partners to engage in sexual activity, and to send sexually explicit photos and videos. ${ }^{5,6}$ TFA is associated with in-person physical and sexual dating abuse. These findings demonstrate that TFA is on the spectrum of abusive behavior, and identifying these 
behaviors may help to prevent additional acts of abuse. .-6 $^{-6}$ Delivery of TFA can describe acts of perpetrating TFA, and receiving TFA can describe being a victim of TFA. Health care clinicians who use the terms "delivered abuse" and "received abuse" are making a deliberate choice to not label a patient as solely a perpetrator or victim of harmful behaviors. ${ }^{7,8}$ This terminology might assist male patients in disclosing TFA by reducing stigma when disclosing abusive behavior. ${ }^{9}$

Data suggest that use of digital tools for abuse is widespread, especially among youth. Among men and women aged $\geq 18$ years, $33 \%$ to $35 \%$ have delivered TFA and $29 \%$ to $33 \%$ have received $\mathrm{TFA}^{6}{ }_{i}$ in addition, $12 \%$ to $13 \%$ of adolescents and young adults aged $<25$ years have delivered or received severe TFA (eg, public humiliation or threats). ${ }^{10}$ In health care settings, $48 \%$ of young adults have delivered or received TFA. ${ }^{4}$ Among a nationally representative sample of adult men and women, $8 \%$ have received TFA over their lifetime. ${ }^{11}$

To our knowledge, there have been no studies reporting TFA delivered or received exclusively among nationally representative adult US men, addressing recent, past-year TFA, or ascertaining the overlap of TFA delivery and receipt. Additionally, there have been no studies that assess the associations of male TFA with health services use and health conditions. The goal of our study was to determine past-year prevalence of TFA among a nationally representative sample of young adult men and to evaluate both delivery and receipt. Our second objective was to examine the associations of TFA with demographics, smartphone ownership, health services use, and mental health problems and substance use.

\section{METHODS}

\section{Participants}

We administered the Men's Health, Fatherhood, and Relationships survey ${ }^{12}$ between August and September 2014 to men aged 18 to 35 years using the online KnowledgePanel, ${ }^{13}$ a probability-based web panel representative of the civilian, noninstitutionalized US population. KnowledgePanel members recruited through 2009 were chosen by randomdigit dialing, and panelists selected in late 2009 onward were chosen by address-based sampling. Those without Internet access receive a web-enabled device and free Internet service. These participants had already agreed to participate in survey research through KnowledgePanel. Survey nonresponders received e-mail reminders at 3 and 10 days, and a telephone reminder at 16 days from initial contact. The survey included self-read informed consent. The Institutional Review Board for Health Sciences and Behavioral Sciences at the University of Michigan approved the study.

\section{Measures}

TFA delivered and received were measured using technology-facilitated abuse items. ${ }^{4}$ Participants were asked if, in the past 12 months, they had done the following to their partner (delivered) or their partner had done the following to them (received) using cell phones, text messages, e-mail, instant messages, or social networking sites such as Facebook: "call names, put down, or insult," "send threatening or harassing messages," "send unwanted and nonstop texts, calls, and online messages asking where at, what doing, and who with," "check partner's cell phone to see who talking to or texting without their permission," or "access partner's online accounts without permission." Respondents reported frequency using a 7-point Likert scale from 1 (never) to 7 (more than 20 times). See Supplemental Appendix for a list of questions regarding TFA provided to survey respondents. Responses were dichotomized into no TFA delivered or received (never to all 5 items) vs any TFA delivered or received (greater than never to any of the items). For analyses we further split TFA into 3 categories: delivered-only, received-only, and both delivered and received.

Health services use was assessed by asking dichotomous questions for connection to primary care (having 1 doctor they usually go to for medical care), emergency department visits (receiving care from a hospital emergency department in the past 2 years), and mental health care visits (ever having seen a psychiatrist, psychologist, or social worker for counseling or therapy) from KnowledgePanel personal health items. ${ }^{14}$ Mental health was measured using a score of greater than 2 on the Patient Health Questionnaire-2 to assess depression. ${ }^{15}$

Substance use problems were assessed from the mean score on the 10-item Alcohol Use Disorders Identification Test for alcohol misuse; possible scores range from 0 to 40 , with higher scores denoting greater misuse. ${ }^{16-18}$ Past-year National Longitudinal Study of Adolescent Health measures were used to assess the mean scores for marijuana use and for prescription opioid pain medication use for nonmedical reasons; both have possible scores ranging from 0 to 6 with higher scores denoting greater use. ${ }^{19}$

Smartphone use was measured using a dichotomous question ("Do you own a smartphone?") from the KnowledgePanel technology and electronics items. ${ }^{14}$ Demographic questions included age; race and ethnicity (non-Hispanic White, non-Hispanic Black, Hispanic, another non-Hispanic race/ethnicity, multiracial non-Hispanic); education (less than high school, high school, some college, bachelor's degree or higher); current employment; and having ever been in relationships with women, men, or both.

\section{Analysis Plan}

We used KnowledgePanel survey weights that account for survey design and nonresponse to obtain nationally representative estimates for nonincarcerated adult men aged 18 to 35 years. Survey weights accounted for demographic factors from the most recent (based on time of data collection) Annual Social and Economic Supplement of the Current Population Survey, conducted in March 2013. The survey response rate was $47 \%(1,346$ of 2,889), with differences in responders and nonresponders addressed by survey weighting. Of the 1,346 men who completed the survey, the 1,079 
men $(80 \%)$ who reported ever having been in a romantic relationship were asked questions about TFA and constituted our analytic sample. Men without a current partner were not excluded. Most men reported being in romantic relationships with women only, so we did not separately analyze men in relationships with women or men.

We measured survey-weighted descriptive statistics with percentages for dichotomous variables and mean scores for continuous variables, with 95\% CIs for each estimate. We conducted survey-weighted multinomial logistic regression analysis to assess associations of demographics, smartphone ownership, health services use, and mental health and substance use problems with categories of TFA delivered-only, TFA received-only, and TFA both delivered and received, compared with the reference category of no TFA. We calculated adjusted odds ratios (AORs) and 95\% CIs. We assessed for multicollinearity in multivariate analyses through a correlation matrix, which showed a Pearson correlation coefficient of less than 0.3 for all independent variables.

All analyses were conducted using Stata version 15.1 (StataCorp LLC). Because we analyzed a subpopulation of the full sample of men completing the survey (ie, only those who reported ever having been in a romantic relationship), we used Stata's subpop command, which correctly calculates standard errors

\section{RESULTS}

The 1,079 men studied had a mean age of 26.5 years, and $57.6 \%$ were of non-Hispanic White race and ethnicity (Table 1). Most, $94.7 \%$, reported relationships with women, while $3.4 \%$ and $1.9 \%$ reported relationships with men or with both women and men, respectively (data not shown).

Nearly one-third of the sample had some experience with TFA in the past year (Table 1). Overall, $4.1 \%$ of men reported delivering TFA only, $8.0 \%$ receiving TFA only, and $25.6 \%$ both delivering and receiving TFA.

In multinomial regression analysis, men were more likely to report TFA delivered-only if they were Hispanic $(\mathrm{AOR}=2.72$; $95 \% \mathrm{CI}, 1.13$ to 6.57$)$, used marijuana $(\mathrm{AOR}=1.31 ; 95 \% \mathrm{CI}$, 1.02 to 1.68$)$, and used prescription opioids for nonmedical reasons $(\mathrm{AOR}=2.86 ; 95 \% \mathrm{CI}, 1.48$ to 5.54 ) (Table 2). They were more likely to report TFA received-only if they identified as Hispanic $(\mathrm{AOR}=2.55 ; 95 \% \mathrm{CI}, 1.01$ to 6.43$)$ and used prescription opioids for nonmedical reasons $(\mathrm{AOR}=2.43$; $95 \% \mathrm{CI}, 1.34$ to 4.39 ), whereas they were less likely to report this category of abuse if they were connected to primary care $(\mathrm{AOR}=0.43 ; 95 \% \mathrm{CI}, 0.22$ to 0.86$)$. Men were more likely to report TFA both delivered and received if they identified as non-Hispanic Black $(\mathrm{AOR}=2.83 ; 95 \% \mathrm{CI}, 1.44$ to 5.58$)$, owned a smartphone $(\mathrm{AOR}=1.80 ; 95 \% \mathrm{CI}, 1.05$ to 3.09$)$, had ever made a mental health care visit $(\mathrm{AOR}=1.86 ; 95 \% \mathrm{CI}$, 1.16 to 2.98$)$, misused alcohol ( $\mathrm{AOR}=1.10 ; 95 \% \mathrm{CI}, 1.04$ to $1.17)$, and used prescription opioids for nonmedical reasons $(\mathrm{AOR}=1.79 ; 95 \% \mathrm{CI}, 1.04$ to 3.08$)$.

\section{DISCUSSION}

Physicians largely do not identify intimate partner violence among male patients, ${ }^{12}$ in part based on limited guidance for identifying and responding to abusive behavior disclosed by adult men. ${ }^{20}$ Ours is the first study to characterize adult male self-reported TFA delivered and received in a nationally representative US population by describing the overlap of both behaviors. We found that almost 1 in 3 young men reported any TFA delivered or received in the past year; by specific category, 1 in 25 reported TFA delivered-only, 1 in 12 TFA

\begin{tabular}{|c|c|}
\hline Measure & Value \\
\hline \multicolumn{2}{|l|}{ Demographics } \\
\hline Age, mean (SD), y & $26.5(26.2-27.0)$ \\
\hline \multicolumn{2}{|l|}{ Race and ethnicity, \% (95\% Cl) } \\
\hline White non-Hispanic & $57.6(54.0-61.1)$ \\
\hline Black non-Hispanic & $11.6(9.2-14.5)$ \\
\hline Hispanic & $21.9(19.0-25.1)$ \\
\hline Another non-Hispanic & $7.1(5.3-9.4)$ \\
\hline Multiracial non-Hispanic & $1.8(1.1-3.0)$ \\
\hline \multicolumn{2}{|l|}{ Education, \% (95\% Cl) } \\
\hline$<$ High school & $14.5(11.6-18.1)$ \\
\hline High school & $29.6(26.4-33.0)$ \\
\hline Some college & $33.0(29.9-36.3)$ \\
\hline Bachelor's degree or higher & $22.9(20.5-25.4)$ \\
\hline Employed, \% (95\% CI) & $69.7(66.1-73.0)$ \\
\hline \multicolumn{2}{|l|}{ Smartphone use } \\
\hline Owns a smartphone, \% (95\% Cl) & $65.3(61.3-69.1)$ \\
\hline \multicolumn{2}{|l|}{ Health service use } \\
\hline Primary care connection, \% (95\% Cl) & $59.6(55.7-63.4)$ \\
\hline $\begin{array}{l}\text { Emergency department visits in past } 2 \\
\text { years, \% }(95 \% \mathrm{Cl})\end{array}$ & $22.3(19.2-25.8)$ \\
\hline Mental health care visits ever, \% $(95 \% \mathrm{Cl})$ & $28.2(24.9-31.9)$ \\
\hline \multicolumn{2}{|l|}{ Mental health problems and substance use } \\
\hline Depression, \% $(95 \% \mathrm{Cl})^{\mathrm{a}}$ & $11.3(9.2-13.9)$ \\
\hline Alcohol misuse, mean (SD) score $\mathrm{b}^{\mathrm{b}}$ & $3.6(3.3-4.0)$ \\
\hline Marijuana use, mean (SD) score ${ }^{c}$ & $0.6(0.5-0.8)$ \\
\hline $\begin{array}{l}\text { Prescription opioid nonmedical use, } \\
\text { mean (SD) score }\end{array}$ & $0.2(0.1-0.2)$ \\
\hline \multicolumn{2}{|l|}{ Technology-facilitated abuse ${ }^{d}$} \\
\hline Any delivered, \% (95\% Cl) & $29.8(26.3-33.5)$ \\
\hline Any received, \% (95\% Cl) & $33.6(30.0-37.5)$ \\
\hline Delivered only, \% (95\% Cl) & $4.1(2.9-5.7)$ \\
\hline Received only, \% (95\% Cl) & $8.0(6.0-10.6)$ \\
\hline Both delivered and received, \% (95\% CI) & $25.6(22.2-29.2)$ \\
\hline None delivered or received, \% (95\% CI) & $62.3(58.4-66.0)$ \\
\hline \multicolumn{2}{|c|}{$\begin{array}{l}\text { a Score of greater than } 2 \text { on Patient Health Questionnaire-2. } \\
\text { b On a scale from } 0 \text { to } 40 \text {, where higher scores denote greater misuse. } \\
\text { 'On a scale from } 0 \text { to } 6 \text {, where higher scores denote greater use. } \\
\text { d Based on respondents' report of having experience with any of } 5 \text { acts of abuse in the } \\
\text { past year. See Methods. }\end{array}$} \\
\hline \multicolumn{2}{|l|}{ Note: Data are weighted for the us population. } \\
\hline
\end{tabular}


Table 2. Multivariate Associations of Characteristics With TFA $(\mathrm{N}=1,079)$

\begin{tabular}{|c|c|c|c|}
\hline Characteristic & $\begin{array}{l}\text { TFA Delivered } \\
\text { Only, AOR } \\
(95 \% \mathrm{Cl})\end{array}$ & $\begin{array}{l}\text { TFA Received } \\
\text { Only, AOR } \\
(95 \% \mathrm{Cl})\end{array}$ & $\begin{array}{l}\text { TFA Both Delivered } \\
\text { and Received, } \\
\text { AOR }(95 \% \mathrm{Cl})\end{array}$ \\
\hline \multicolumn{4}{|l|}{ Demographics } \\
\hline Age: per year & $1.05(0.95-1.16)$ & $0.94(0.87-1.02)$ & $0.96(0.92-1.01)$ \\
\hline \multicolumn{4}{|l|}{ Race/ethnicity a } \\
\hline Black non-Hispanic & $1.02(0.20-5.36)$ & $1.19(0.35-4.03)$ & $2.83^{b}(1.44-5.58)$ \\
\hline Hispanic & $2.72^{\complement}(1.13-6.57)$ & $2.55^{c}(1.01-6.43)$ & $1.53(0.89-2.63)$ \\
\hline Another non-Hispanic & $1.95(0.44-8.65)$ & $2.95(0.79-11.0)$ & $2.54(0.96-6.72)$ \\
\hline Multiracial non-Hispanic & $0.22(0.02-3.21)$ & $1.87(0.61-5.72)$ & $0.31(0.07-1.43)$ \\
\hline \multicolumn{4}{|l|}{ Education ${ }^{d}$} \\
\hline High school education & $0.48(0.12-1.86)$ & $0.40(0.06-2.55)$ & $0.90(0.33-2.47)$ \\
\hline Some college & $1.51(0.44-5.20)$ & $0.50(0.08-2.94)$ & $0.92(0.33-2.52)$ \\
\hline Bachelor's degree or higher & $1.36(0.40-4.69)$ & $0.72(0.12-4.47)$ & $0.77(0.27-2.14)$ \\
\hline Employed & $4.25(0.62-29.2)$ & $1.04(0.38-2.82)$ & $1.61(0.90-2.88)$ \\
\hline \multicolumn{4}{|l|}{ Smartphone use } \\
\hline Owns a smartphone & $0.72(0.29-1.82)$ & $0.70(0.29-1.69)$ & $1.80^{\mathrm{b}}(1.05-3.09)$ \\
\hline \multicolumn{4}{|l|}{ Health service use } \\
\hline Primary care connection & $0.83(0.39-1.77)$ & $0.43^{b}(0.22-0.86)$ & $1.19(0.78-1.83)$ \\
\hline Emergency department visits & $0.83(0.33-2.08)$ & $1.14(0.49-2.62)$ & $1.49(0.89-2.50)$ \\
\hline Mental health care visits & $0.71(0.28-1.82)$ & $0.95(0.48-1.89)$ & $1.86^{\mathrm{b}}(1.16-2.98)$ \\
\hline \multicolumn{4}{|l|}{$\begin{array}{l}\text { Mental health problems and } \\
\text { substance use }\end{array}$} \\
\hline Depression & $1.48(0.49-4.40)$ & $0.41(0.09-1.85)$ & $0.97(0.45-2.10)$ \\
\hline Alcohol misuse & $1.00(0.91-1.10)$ & $1.06(0.98-1.15)$ & $1.10^{\mathrm{e}}(1.04-1.17)$ \\
\hline Marijuana use & $1.31^{b}(1.02-1.68)$ & $0.83(0.64-1.07)$ & $1.08(0.94-1.24)$ \\
\hline $\begin{array}{l}\text { Prescription opioid non- } \\
\text { medical use }\end{array}$ & $2.86^{c}(1.48-5.54)$ & $2.43^{c}(1.34-4.39)$ & $1.79^{b}(1.04-3.08)$ \\
\hline \multicolumn{4}{|c|}{ AOR $=$ adjusted odds ratio; TFA $=$ technology-facilitated abuse. } \\
\hline \multicolumn{4}{|l|}{$\begin{array}{l}\text { a Reference group is White non-Hispanic. } \\
\text { b } P<.01 . \\
\text { c } P<.05 \text {. } \\
\text { d Reference group is less than high school. } \\
\text { e } P<.001 .\end{array}$} \\
\hline \multicolumn{4}{|c|}{$\begin{array}{l}\text { Notes: Results of multinomial logistic regression analysis using no TFA as the reference category. Data are weighted for the US } \\
\text { population. }\end{array}$} \\
\hline
\end{tabular}

in the United States support health care professionals asking men about intimate partner violence, ${ }^{12}$ primary care clinicians can consider querying not only about intimate partner violence but also about TFA among male patients. Men who reported ever having mental health care visits had higher odds of TFA both delivered and received. Given this association, primary care physicians can consider assessing TFA among male patients who use mental health services. Three screening tools for intimate partner violence-the Hurt, Insult, Threaten, and Scream Brief Domestic Violence tool, the Partner Violence Screen, and the Index of Spousal Abuse-have been validated in women and are now showing promise in primary care and emergency medicine settings for identifying male intimate partner violence perpetration or victimization. ${ }^{23,24}$ Although these tools still need further validation in male patients, primary care clinicians can consider expanding some of the tools' questions to include TFA.

Alcohol misuse, marijuana use, and prescription pain medication use for nonmedical reasons were associated with increased odds of TFA, findings that are consistent with correlates of such abuse among adolescents and youth. ${ }^{25-27}$ Although depression, education level, and employment status have been associated with increased intimate part- received-only, and 1 in 4 TFA both delivered and received. These rates are similar to national past-year estimates of male intimate partner violence victimization, with $5 \%$ experiencing contact sexual violence, physical violence, or stalking, ${ }^{21}$ and $18 \%$ experiencing psychological aggression. ${ }^{22}$ Notably, the largest group of men reporting TFA were those in the group both delivering and receiving abuse. This finding is similar to other data demonstrating that the largest group of men reporting physical intimate partner violence were those both receiving and delivering it, compared with those only delivering or only receiving. ${ }^{12}$ Taken together, these results highlight the complexity of identifying and responding to intimate partner violence and TFA among men, given that delivery and receipt commonly occur together.

Men who had a primary care physician had lower odds of reporting TFA received. Given that 9 out of 10 young men ner violence, ${ }^{28,29}$ these characteristics were not correlated with TFA in our study. This difference may reflect our controlling for other factors typically associated with intimate partner violence, ${ }^{28,29}$ or possibly differing effects of depression, education level, and employment status for men compared with women. Men identifying as non-Hispanic Black had increased odds of TFA both delivered and received, and men identifying as Hispanic had increased odds of TFA delivered-only and received-only. Other national studies have shown lower lifetime physical and sexual violence and stalking victimization reported by White men as compared with self-identified Black, Native American, or multiracial men, ${ }^{22}$ and large health carebased studies have shown increased odds of physical intimate partner violence perpetration and victimization among young men of Black vs White or other race. ${ }^{17}$ These racial and ethnic findings likely represent unmeasured socioeconomic factors, 
neighborhood factors, or both. Additionally, the observed disparities by race demonstrate the need for culturally and contextually designed interventions to equitably address these health disparities among minority men. ${ }^{30,31}$

Men who owned smartphones were more likely to report TFA both delivered and received. Primary care physicians may use this association to consider developing and delivering TFA interventions by smartphones. Digital interventions are being used for alcohol and drug use disorders, ${ }^{32,33}$ and these substance-use interventions could be adapted to include TFA. Additionally, tailored online intimate partner violence interventions that show success for helping women experiencing intimate partner violence could be expanded to include men while including TFA-specific interventions. ${ }^{34}$

Our cross-sectional survey can assess only associations with and not causation of TFA among men. Experiences of TFA delivered and received were self-reported measures without context or input from partners and did not include reports of in-person or technology-facilitated physical or sexual abuse. Our data were collected in 2014, and given the continued expansion of communication technologies and applications, TFA prevalence may have changed since then. Additionally, we did not assess men's sending or receiving of sexually explicit photos, and we did not have questions on transgender and cisgender status, or gender identity. Future research can measure expanded forms of TFA and gender identity among men. With these limitations in mind, our study contributes to physician understanding of TFA by demonstrating that past-year TFA was prevalent and associated with primary care and mental health service use, alcohol misuse, and substance use. Primary care physicians can consider assessing TFA among their male patients and developing interventions to mitigate this behavior.

\section{Read or post commentaries in response to this article.}

Key words: technology-facilitated abuse; intimate partner violence, prevalence; young men; screening; primary care

Submitted September 20, 2020; submitted, revised, May 3, 2021; accepted May 25, 2021.

Funding support: This research was supported by the Robert Wood Johnson Foundation and the Veterans Affairs Clinical Scholars Program at the University of Michigan.

Disclaimer: The views expressed are solely those of the authors and do not necessarily represent official views of the authors' affiliated institutions or funders.

Previous presentation: Presented at the Society for the Advancement of Violence and Injury Research Annual Conference; April 27, 2020; virtual conference.

\section{Supplemental materials}

\section{References}

1. Pew Research Center. 2019 mobile fact sheet. Published Jun 12, 2019. Accessed Sep 20, 2020. https://www.pewresearch.org/internet/fact-sheet/ mobile/

2. Lenhart A, Duggan M. Couples, the internet, and social media: how American couples use digital technology to manage life, logistics, and emotional intimacy within their relationships. Pew Research Center. Published Feb 11, 2014. Accessed Sep 20, 2020. https://www.pewresearch.org/ internet/2014/02/11/couples-the-internet-and-social-media/
3. Draucker CB, Martsolf DS. The role of electronic communication technology in adolescent dating violence. J Child Adolesc Psychiatr Nurs. 2010;23(3):133142. 10.1111/j.1744-6171.2010.00235.x

4. Epstein-Ngo QM, Roche JS, Walton MA, Zimmerman MA, Chermack ST, Cunningham RM. Technology-delivered dating aggression: risk and promotive factors and patterns of associations across violence types among high-risk youth. Violence Gend. 2014;1(3):131-133. 10.1089/vio.2014.0018

5. Reed LA, Tolman RM, Ward LM. Snooping and sexting: digital media as a context for dating aggression and abuse among college students. Violence Against Women. 2016;22(13):1556-1576.

6. Watkins LE, Maldonado RC, DiLillo D. The Cyber Aggression in Relationships Scale: a new multidimensional measure of technologybased intimate partner aggression. Assessment. 2018;25(5):608-626. 10.1177/1073191116665696

7. Hamby S. Self-report measures that do not produce gender parity in intimate partner violence: a multi-study investigation. Psychol Violence. 2016; 6(2):323-335

8. Tu J, Penti B. How we talk about "perpetration of intimate partner violence" matters. J Am Board Fam Med. 2020;33(5):809-814. 10.3122/ jabfm.2020.05.200066

9. Machado A, Hines D, Matos M. Help-seeking and needs of male victims of intimate partner violence in Portugal. Psychol Men Masc. 2016;17(3):255264. $10.1037 /$ men 0000025

10. Leisring PA, Giumetti GW. Sticks and stones may break my bones, but abusive text messages also hurt: development and validation of the Cyber Psychological Abuse scale. Partn Abus. 2014;5(3):323-341.

11. Ybarra M, Price-Feeney M, Lenhart A, Zickuhr K. Intimate partner digital abuse: report. Data \& Society. Published Jan 18, 2017. Accessed Sep 20, 2020. https://datasociety.net/library/intimate-partner-digital-abuse/

12. Walsh TB, Seabrook RC, Tolman RM, Lee SJ, Singh V. Prevalence of intimate partner violence and beliefs about partner violence screening among young men. Ann Fam Med. 2020;18(4):303-308. 10.1370/afm.2536

13. Ipsos, KnowledgePanel. Accessed Sep 20, 2020. https://www.ipsos.com/ en-us/solutions/public-affairs/knowledgepanel

14. Ipsos. Panel Book: KnowledgePanel Brings You a Probability-Based Online Sample. Ipsos; 2019. Accessed Sep 20, 2020. https://www.ipsos.com/sites/ default/files/june-2020_kp_book-1.pdf

15. Kroenke K, Spitzer RL, Williams JB. The Patient Health Questionnaire-2: validity of a two-item depression screener. Med Care. 2003;41(11):12841292. 10.1097/01.MLR.0000093487.78664.3C

16. Saunders JB, Aasland OG, Babor TF, de la Fuente JR, Grant M. Development of the Alcohol Use Disorders Identification Test (AUDIT): WHO collaborative project on early detection of persons with harmful alcohol consumption-II. Addiction. 1993;88(6):791-804. 10.1111/j.1360-0443.1993.tb02093.x

17. Singh V, Walton MA, Whiteside LK, et al. Dating violence among male and female youth seeking emergency department care. Ann Emerg Med. 2014; 64(4):405.e1-412.e1.

18. Mahoney CT, Iverson KM. The roles of alcohol use severity and posttraumatic stress disorder symptoms as risk factors for women's intimate partner violence experiences. J Womens Health (Larchmt). 2020;29(6):827-836. 10.1089/jwh.2019.7944

19. Harris KM, Udry JR, Bearman PS. The National Longitudinal Study of Adolescent Health: In Home Questionnaire Codebook Wave III, Section 28, Tobacco, Alcohol, Drugs, Self Image. Accessed Sep 20, 2020. https:// addhealth.cpc.unc.edu/documentation/codebooks/

20. Singh V, Tolman R, Walton M, Chermack S, Cunningham R. Characteristics of men who perpetrate intimate partner violence. J Am Board Fam Med. 2014; 27(5):661-668. 10.3122/jabfm.2014.05.130247

21. Smith SG, Zhang X, Basile KC, et al. The National Intimate Partner and Sexual Violence Survey: 2015 Data Brief - Updated Release. National Center for Injury Prevention and Control, Centers for Disease Control and Prevention; 2018. https://www.cdc.gov/violenceprevention/pdf/2015data-brief508.pdf

22. Black MC, Basile KC, Breiding MJ, et al. The National Intimate Partner and Sexual Violence Survey (NISVS): 2010 Summary Report. National Center for Injury Prevention and Control, Centers for Disease Control and Prevention; 2011. https://www.cdc.gov/violenceprevention/pdf/nisvs_executive_summary-a.pdf 
23. Kapur NA, Windish DM. Optimal methods to screen men and women for intimate partner violence: results from an internal medicine residency continuity clinic. J Interpers Violence. 2011;26(12):2335-2352. 10.1177/08862605 10383034

24. Avegno J, Harrison N, Mills TJ, Mills LD. Three brief tools for identification of male intimate partner violence in the emergency department. Ann Emerg Med. Oct;2004;44(4 Suppl):59.

25. Flach RMD, Deslandes SF. Cyber dating abuse in affective and sexual relationships: a literature review. Cad Saude Publica. 2017;33(7):e00138516. 10.15090/0102-311X00138516

26. Flanagan JC, Leone RM, Gilmore AK, McClure EA, Gray KM. Association of cannabis use with intimate partner violence among couples with substance misuse. Am J Addict. 2020;29(4):323-330. 10.1111/ajad.13025

27. Smith PH, Homish GG, Leonard KE, Cornelius JR. Intimate partner violence and specific substance use disorders: findings from the National Epidemiologic Survey on Alcohol and Related Conditions. [published correction appears in Psychol Addict Behav. 2012 Jun;26(2):254]. Psychol Addict Behav. 2012;26(2):236-245. 10.1037/a0024855

28. Zweig JM, Lachman P, Yahner J, Dank M. Correlates of cyber dating abuse among teens. J Youth Adolesc. 2014;43(8):1306-1321. 10.1007/ s10964-013-0047-x
29. Capaldi DM, Knoble NB, Shortt JW, Kim HK. A systematic review of risk factors for intimate partner violence. Partner Abuse. 2012;3(2):231-280. 10.1891/1946-6560.3.2.231

30. Benson ML, Woolredge J, Thistlethwaite AB, Fox GL. The correlation between race and domestic violence is confounded with community. Soc Probl. 2004;51(3):326-342.

31. Gracia E, López-Quílez A, Marco M, Lila M. Neighborhood characteristics and violence behind closed doors: the spatial overlap of child maltreatment and intimate partner violence. PLoS One. 2018;13(6):e0198684. 10.1371/ journal.pone.0198684

32. Cochran G, Stitzer M, Campbell AN, Hu MC, Vandrey R, Nunes EV. Webbased treatment for substance use disorders: differential effects by primary substance. Addict Behav. 2015;45:191-194.

33. Marsch LA, Campbell A, Campbell C, et al. The application of digital health to the assessment and treatment of substance use disorders: the past, current, and future role of the National Drug Abuse Treatment Clinical Trials Network. J Subst Abuse Treat. 2020;112S:4-11.

34. Ford-Gilboe M, Varcoe C, Scott-Storey K, et al. Longitudinal impacts of an online safety and health intervention for women experiencing intimate partner violence: randomized controlled trial. BMC Public Health. 2020;20(1):260. 